\title{
The Potential for the Internet and Telehealth in Caregiver Support. Comment on "Using Technology to Facilitate Fidelity Assessments: The Tele-STAR Caregiver Intervention"
}

Kohei Kajiwara ${ }^{1}, \mathrm{PhD}$; Jun Kako ${ }^{2}, \mathrm{PhD}$; Hiroko Noto ${ }^{3}, \mathrm{PhD}$; Yasufumi Oosono ${ }^{4}, \mathrm{PhD}$; Masamitsu Kobayashi ${ }^{4}, \mathrm{MSN}$

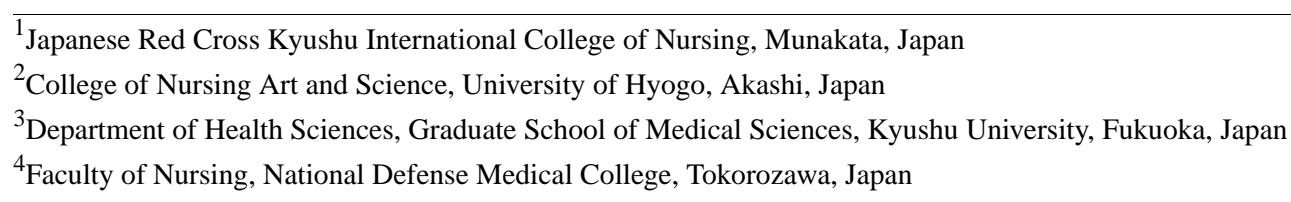

Corresponding Author:

Kohei Kajiwara, $\mathrm{PhD}$

Japanese Red Cross Kyushu International College of Nursing

1-1 Asty Munakata-City

Fukuoka-Prefecture 811-4157

Japan

Phone: 81940357030

Email: k-kajiwara@jrckicn.ac.jp

\section{Related Article:}

Comment on: https://www.jmir.org/2019/5/e13599/

(J Med Internet Res 2021;23(2):e14953) doi: 10.2196/14953

\section{KEYWORDS}

dementia; caregiver; technology

We read with interest the recent paper entitled "Using Technology to Facilitate Fidelity Assessments: The Tele-STAR Caregiver Intervention" by Lindauer et al [1]. The authors concluded that Tele-STAR contributed to low caregiver burden and showed good fidelity as an intervention method.

Internet-based videoconferencing technology is an important source of support for caregivers of persons with dementia. Researchers have previously demonstrated the positive potential of computer-mediated interventions and technology-based cognitive behavioral therapy interventions for caregivers of people with dementia [2,3]. Others have raised the difficulties in measuring intervention fidelity in a consistent manner [4,5], which raises the importance of consistency when considering fidelity evaluations. Moreover, as the study reported results that may be attributed to both in-home and telehealth intervention experiences of participants, it may be useful to consider the interplay of these aspects.

Lindauer and colleagues [1] reported a slight reduction in caregiver burden, attributed to an improvement in caregivers' responses to patients with dementia, facilitated by the Tele-STAR intervention. Caregiver burden is an important consideration in the field of dementia care. A recent study found an internet-based intervention to be effective in increasing the positive aspect of subjective appraisal for caregivers of persons with dementia [6]. In addition, we have studied the subjective appraisal of both negative and positive aspects in this population [7]. Assessments that take into account both sides of subjective appraisal are capable of providing a broad understanding of a caregiver's context, and we would argue that an outcome that takes both into account would be more useful than current practices allow for.

The support that can be offered to caregivers using internet-driven technologies should continue to be explored, and the study conducted by Lindauer and colleagues [1] provides useful data in this regard. We agree that internet-based interventions will be beneficial to caregivers of persons with dementia in the future.

\section{Editorial Notice}

The corresponding author of "Using Technology to Facilitate Fidelity Assessments: The Tele-STAR Caregiver Intervention" declined to respond to this letter. 


\section{Conflicts of Interest}

None declared.

\section{References}

1. Lindauer A, McKenzie G, LaFazia D, McNeill L, Mincks K, Spoden N, et al. Using Technology to Facilitate Fidelity Assessments: The Tele-STAR Caregiver Intervention. J Med Internet Res 2019 May 24;21(5):e13599 [FREE Full text] [doi: 10.2196/13599] [Medline: 31127721$]$

2. McKechnie V, Barker C, Stott J. Effectiveness of computer-mediated interventions for informal carers of people with dementia-a systematic review. Int Psychogeriatr 2014 Oct;26(10):1619-1637 [FREE Full text] [doi: 10.1017/S1041610214001045] [Medline: 24989249]

3. Scott JL, Dawkins S, Quinn MG, Sanderson K, Elliott KE, Stirling C, et al. Caring for the carer: a systematic review of pure technology-based cognitive behavioral therapy (TB-CBT) interventions for dementia carers. Aging Ment Health 2016 Aug;20(8):793-803. [doi: 10.1080/13607863.2015.1040724] [Medline: 25978672]

4. Godwin KM, Mills WL, Anderson JA, Kunik ME. Technology-driven interventions for caregivers of persons with dementia: a systematic review. Am J Alzheimers Dis Other Demen 2013 May;28(3):216-222 [FREE Full text] [doi: 10.1177/1533317513481091] [Medline: 23528881]

5. Nguyen TA, Nguyen H, Pham T, Nguyen TH, Hinton L. A cluster randomized controlled trial to test the feasibility and preliminary effectiveness of a family dementia caregiver intervention in Vietnam: The REACH VN study protocol. Medicine (Baltimore) 2018 Oct;97(42):e12553 [FREE Full text] [doi: 10.1097/MD.0000000000012553] [Medline: 30334942]

6. Moskowitz JT, Cheung EO, Snowberg KE, Verstaen A, Merrilees J, Salsman JM, et al. Randomized controlled trial of a facilitated online positive emotion regulation intervention for dementia caregivers. Health Psychol 2019 May;38(5):391-402 [FREE Full text] [doi: 10.1037/hea0000680] [Medline: $\underline{\text { 31045422] }}$

7. Kajiwara K, Noto H, Yamanaka M. Changes in caregiving appraisal among family caregivers of persons with dementia: A longitudinal study over 12 months. Psychogeriatrics 2018 Nov;18(6):460-467. [doi: 10.1111/psyg.12360] [Medline: 30066482]

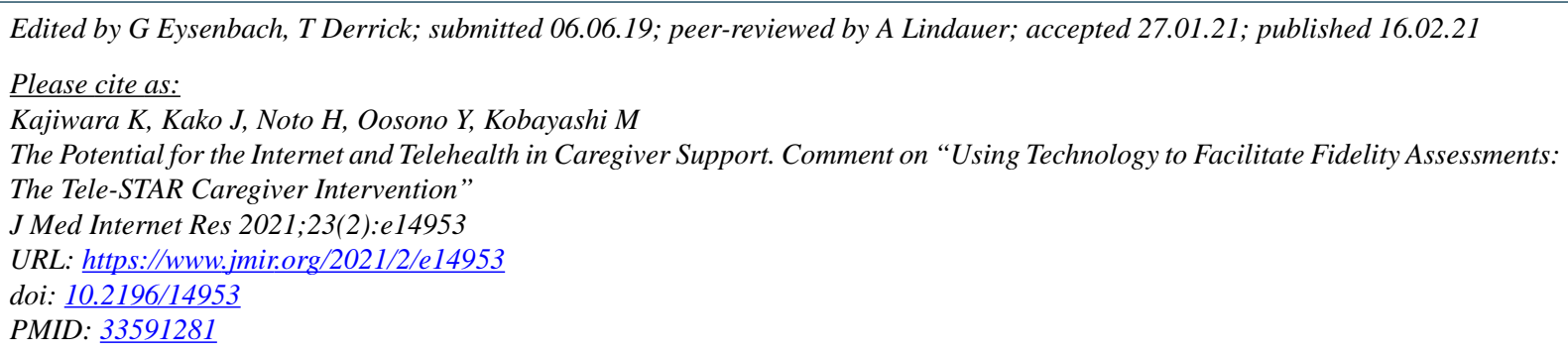

CKohei Kajiwara, Jun Kako, Hiroko Noto, Yasufumi Oosono, Masamitsu Kobayashi. Originally published in the Journal of Medical Internet Research (http://www.jmir.org), 16.02.2021. This is an open-access article distributed under the terms of the Creative Commons Attribution License (https://creativecommons.org/licenses/by/4.0/), which permits unrestricted use, distribution, and reproduction in any medium, provided the original work, first published in the Journal of Medical Internet Research, is properly cited. The complete bibliographic information, a link to the original publication on http://www.jmir.org/, as well as this copyright and license information must be included. 